\title{
Suppressive Activity of Vitamin D3 on Matrix Metalloproteinase Production From Cholesteatoma Keratinocytes In Vitro
}

\author{
Hitome Kobayashi, Kazuhito Asano, Ken-ichi Kanai, and Harumi Suzaki \\ Department of Otorhinolaryngology, Showa University School of Medicine, \\ 1-5-8 Hatanodai, Shinagawa-ku Tokyo 142-8666, Japan
}

Received 2 May 2005; accepted 19 May 2005

\begin{abstract}
There is much evidence that degradation of the extracellular matrix is essential for the development of cholesteatomas and that this is induced by activation of matrix metalloproteinases (MMPs). Vitamin D3 (VD3) has several well-recognised biological activities, including suppression of MMP production. The present study, therefore, was undertaken to examine whether VD3 could suppress MMP production from cholesteatoma keratinocytes in vitro. Keratinocytes $\left(2.5 \times 10^{5}\right.$ cells $\left./ \mathrm{mL}\right)$ induced from cholesteatoma tissue specimens were cultured with various concentrations of VD3. After one hour, lipopolysaccharide was added to the cell cultures at $100 \mu \mathrm{g} / \mathrm{mL}$. The culture supernatants were then collected and assayed for MMP-1 and MMP-3 by ELISA. We also used ELISA to measure the levels of both TIMP (tissue inhibitor of metalloproteinase)-1 and TIMP-2 in culture supernatants. Addition of VD3 into keratinocyte cultures caused the suppression of MMP and TIMP production, which was increased by LPS stimulation. This was dose-dependent. The present results showing the suppressive activity of VD3 on the production of MMPs, which are responsible for tissue remodeling, strongly suggest that VD3 would be a good candidate for an agent in the medical treatment of, or prophylaxis for, cholesteatomas.
\end{abstract}

\section{INTRODUCTION}

The cholesteatoma is well recognised as a skin growth that occurs in an abnormal location, the middle ear behind the eardrum. It is also accepted that, over time, the cholesteatoma can increase in size and destroy the surrounding delicate bones of the middle ear. Although much effort has been made to understand the mechanisms of cholesteatoma formation, the precise mechanisms are not well understood [1].

The extracellular matrix (ECM) and cell to ECM interaction is essential for cell proliferation and migration $[1,2]$. It is well established that degradation of both basement membrane and ECM is important for carcinoma invasion, metastasis, and inflammatory proteolytic events [3]. Furthermore, degradation of the tissues is also accepted to be accomplished by the cooperative action of several types of proteolytic enzymes, including matrix metalloproteinases (MMPs) $[1,3]$. In this regard,

Corresponding and reprint requests to Hitome Kobayashi, Department of Otorhinolaryngology, Showa University School of Medicine, 1-5-8 Hatanodai, Shinagawa-ku, Tokyo 142-8666, Japan; hitomek@med.showa-u.ac.jp several researchers examined the presence of MMPs in cholesteatoma tissues, and revealed the extensive expression of MMPs, such as MMP-1, $-2,-3$, and $-9[1,3,4]$. The MMP inhibitor, ilomastat, has been effective in reducing protease activity and tissue destruction in alkali-injured rabbit corneas [5] and the chinchilla middle ear infected with Pseudomonas aeruginosa [6]. From these reports, it is reasonable to speculate that the use of MMP inhibitors may prevent cholesteatoma progression. However, to the best of our knowledge, no reports have appeared in the literature, examining the influence of MMP inhibitor(s) on the prevention of the induction and the progression of cholesteatomas.

$1 \alpha$,25-dihydroxyvitamin D3 (VD3) has several wellrecognised biological effects on cell proliferation and differentiation, including tissue remodeling, which is mediated by MMPs $[7,8,9]$. These biological effects of VD3 have been reported to be due, at least in part, to its suppressive effect on MMP production from chondrocytes and osteoblastic cells. The present study was therefore undertaken to examine whether VD3 could be used for the medical treatment of and prophylaxis for cholesteatomas by examining the influence of VD3 on MMP production from keratinocytes in vitro. 


\section{MATERIALS AND METHODS}

\section{Reagent}

VD3 was donated from TEIJIN Co, Ltd (Tokyo, Japan). This was dissolved in dymethyl sulfoxide (DMSO) at a concentration of $1 \times 10^{-3} \mathrm{M}$ and then diluted with keratinocyte-SFM (SFM; SIGMA CHEMICALS Co Ltd, St Louis, Mo, USA) at appropriate concentrations for experiments. Lipopolysaccharide (LPS) extracted from Escherichia coli was purchased from SIGMA CHEMICALS Co, Ltd.

\section{Induction of keratinocytes}

Cholesteatomas were obtained surgically from five patients under written informed consent, and the entire study was approved by the Ethics Committee of Showa University. Tissue samples were digested with 2.4 U/mL Dispase II (Boehringer Mannhaim, Germany) for 12 hours at $4^{\circ} \mathrm{C}$. Epithelial sheets were then dissected, cut into small pieces with scissors, and dissociated with $0.2 \%$ trypsin (GIBCO BRL, Gaithersburg, Md, USA) for 30 minutes at $37^{\circ} \mathrm{C}$. The dissociated cells were washed several times with SFM supplemented with $500 \mu \mathrm{g} / \mathrm{mL}$ streptomycin, $500 \mathrm{U}$ penicillin, and $5.0 \mu \mathrm{g} / \mathrm{mL}$ amphotericin B. The cells were then seeded at a density of $1 \times 10^{6}$ cells/100-mm culture dishes, and the dishes were placed at $37^{\circ} \mathrm{C}$ in a humidified atmosphere containing $5 \% \mathrm{CO}_{2}$. The medium was changed every 3 days for 2-3 weeks until confluence was attained. Subsequently, the cells were trypsinised, characterised with involucrinin staining, and used as keratinocytes.

\section{Cell culture}

The cells were washed several times with SFM and introduced into each well of 24-well culture plates at a concentration of $2.5 \times 10^{5}$ cells $/ \mathrm{mL}$ in a volume of $1.0 \mathrm{~mL}$. The cells were then stimulated with $100 \mu \mathrm{g} / \mathrm{mL}$ LPS in the presence or absence of various concentrations of VD3 in a final volume of $2.0 \mathrm{~mL}$. VD3 treatment was started 60 minutes before LPS stimulation. After 24 hours, the culture medium was removed and centrifuged, and the supernatants were stored at $-40^{\circ} \mathrm{C}$ until use. For the examination of the influence of VD3 on mRNA expression for MMPs and TIMPs, the cells were cultured in a similar manner for 12 hours, and the cells were obtained and stored at $-80^{\circ} \mathrm{C}$ until processed.

\section{Assay for MMPs and TIMPs in culture supernatants}

MMP-2, MMP-9, TIMP-1, and TIMP-2 levels in culture supernatants were assayed using commercially available human MMP and TIMP ELISA test kits (Amersham Biosciences, Bucks, UK) according to the manufacturer's recommendation.

\section{Assay for mRNA expression}

mRNA was extracted from keratinocytes using $\mu$ MACS mRNA isolation kits (Milteny Biotec $\mathrm{GmbH}$, Bergisch Gladbach, Germany) according to the manu- facturer's instructions. The first-strand cDNA synthesis from $1.0 \mu \mathrm{g}$ mRNA was performed using the Super Script Preamplification System for cDNA synthesis (GIBCO $\mathrm{BRL}$ ). The polymerase chain reaction (PCR) mixture consisted of $1.0 \mu \mathrm{L}$ of sample cDNA solution, $3.3 \mu \mathrm{L}$ of $10 \times$ PCR buffer (Takara Shuzo Co, Ltd, Shiga, Japan), $2.6 \mu \mathrm{L}$ of dNTP mixture (Takara Shuzo), $1.0 \mu \mathrm{L}$ of both sense and antisense primers, $0.2 \mu \mathrm{L}$ of Taq DNA polymerase (Takara Shuzo), and distilled water to give a final volume of $30 \mu \mathrm{L}$. The primers used for RT-PCR were 5'-AGATCTTCTTCTTCAAGGACCGGTT-3' (sense) and 5'-GGCTGGTCAGTGGCTTGGGGTA-3' (anti-sense) for MMP-2 [10], 5' -CCTCTGATGGCCCAGAATTGA-3' (sense) and 5'-GAAATTGGCCACTCCCTGGGT-3' (anti-sense) for MMP-3 [11], 5'-CACCCACAGACGGCCTTCTGCAAT-3' (sense) and 5' -AGTGTAGGTCTTGGTGAAGCC-3' (anti-sense) for TIMP-1 [11] 5' CTCGCTGGACGTTGGAGGAAAGAA-3' (sense) and 5' -AGCCCATCTGGTACCTGTGGTTCA-3' (anti-sense) for TIMP-2 [12], 5' -CGGAACCGCTCATTGCC-3' and $5^{\prime}$-ACCCACACTGTGCCCATCTA- $3^{\prime}$ for $\beta$-actin [10].

The PCR conditions were as follows: 4 minutes at $94^{\circ} \mathrm{C}$, followed by 30 cycles of 30 seconds at $94^{\circ} \mathrm{C}$, 30 seconds at $58^{\circ} \mathrm{C}$, and 30 seconds at $72^{\circ} \mathrm{C}$. After cycling, there was a DNA extension period of 4 minutes at $72^{\circ} \mathrm{C}$. Each PCR product $(10 \mu \mathrm{L})$ was run on $3 \%$ agarose gels, visualised with a UV illuminator after SYBR Green staining (BioWhittaker Molecular Applications, Rockland, Me) and photographed. The intensity of the mRNA levels was corrected by $\beta$-actin transcripts calculated with a densitometer.

\section{Statistical analysis}

The statistical significance of the difference between the control and experimental data was analysed using ANOVA followed by Fisher's PLSD test. A $P$ value $<.05$ was accepted as statistically significant.

\section{RESULTS}

\section{Influence of VD3 on the production of MMP and TIMP from keratinocytes in vitro}

The first set of experiments was designed to examine the influence of VD3 on MMPs production from keratinocytes in response to LPS stimulation. Keratinocytes at a concentration of $2.5 \times 10^{5}$ cells $/ \mathrm{mL}$ were stimulated with $100.0 \mu \mathrm{g} / \mathrm{mL}$ LPS for 24 hours, and MMP-2 and MMP-3 levels in culture supernatants were examined by ELISA. As shown in Figure 1, addition of VD3 into cell cultures at less than $10^{-8} \mathrm{M}$ did not cause the suppression of MMP-2 production from keratinocytes: the culture supernatants obtained from cells treated with $10^{-8} \mathrm{M}$ contained similar levels of MMP-2 to those in control cultures. However, VD3 at more than $10^{-7} \mathrm{M}$ significantly suppressed the ability of cells to produce MMP-2 induced by LPS stimulation (Figure 1). We next 

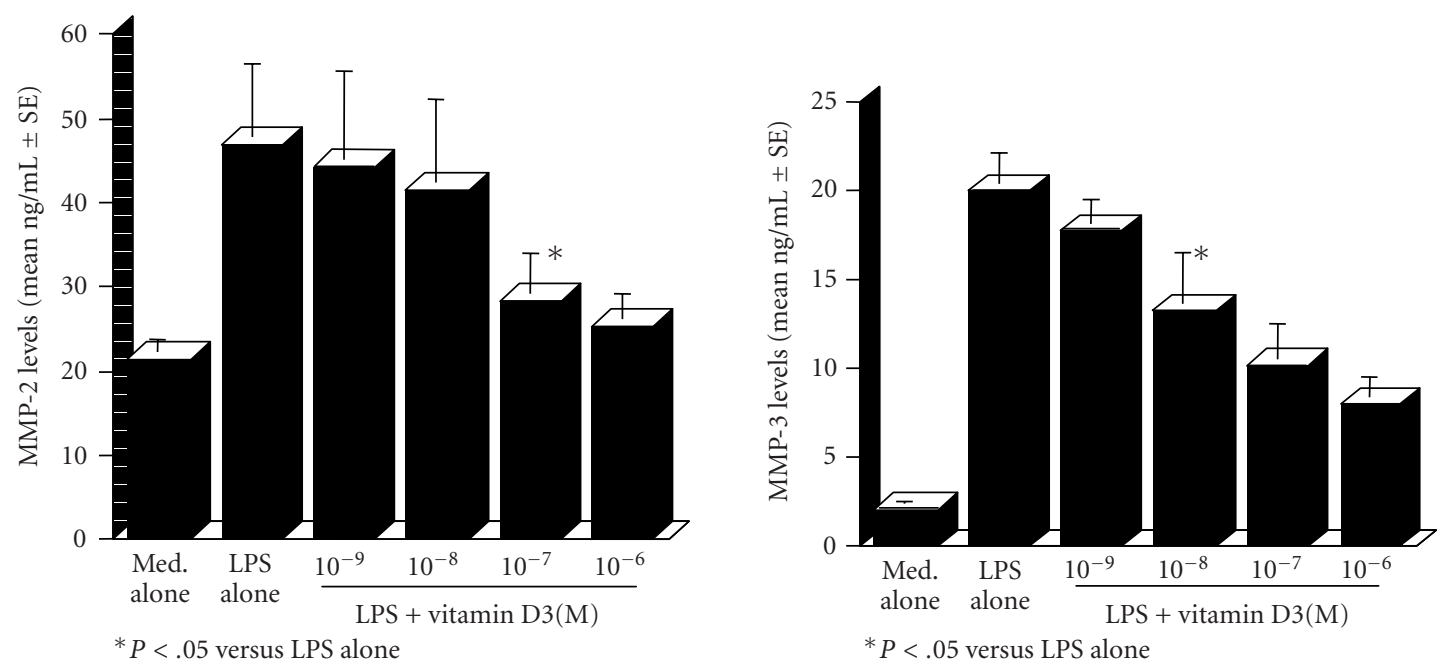

FIgURE 1. Suppressive activity of vitamin D3 on MMP-2 and MMP-3 production from keratinocytes in vitro. Keratinocytes $(2.5 \times$ $10^{5}$ cells $/ \mathrm{mL}$ ) derived from cholesteatoma tissues were stimulated with $100 \mu \mathrm{g} / \mathrm{mL}$ lipopolysaccharide (LPS) in the presence of various concentrations of vitamin D3 for 24 hours. MMP-2 levels in culture supernatants were examined by ELISA. Each set of data was expressed as the mean $\mathrm{ng} / \mathrm{mL} \pm \mathrm{SEM}$ of five different subjects.
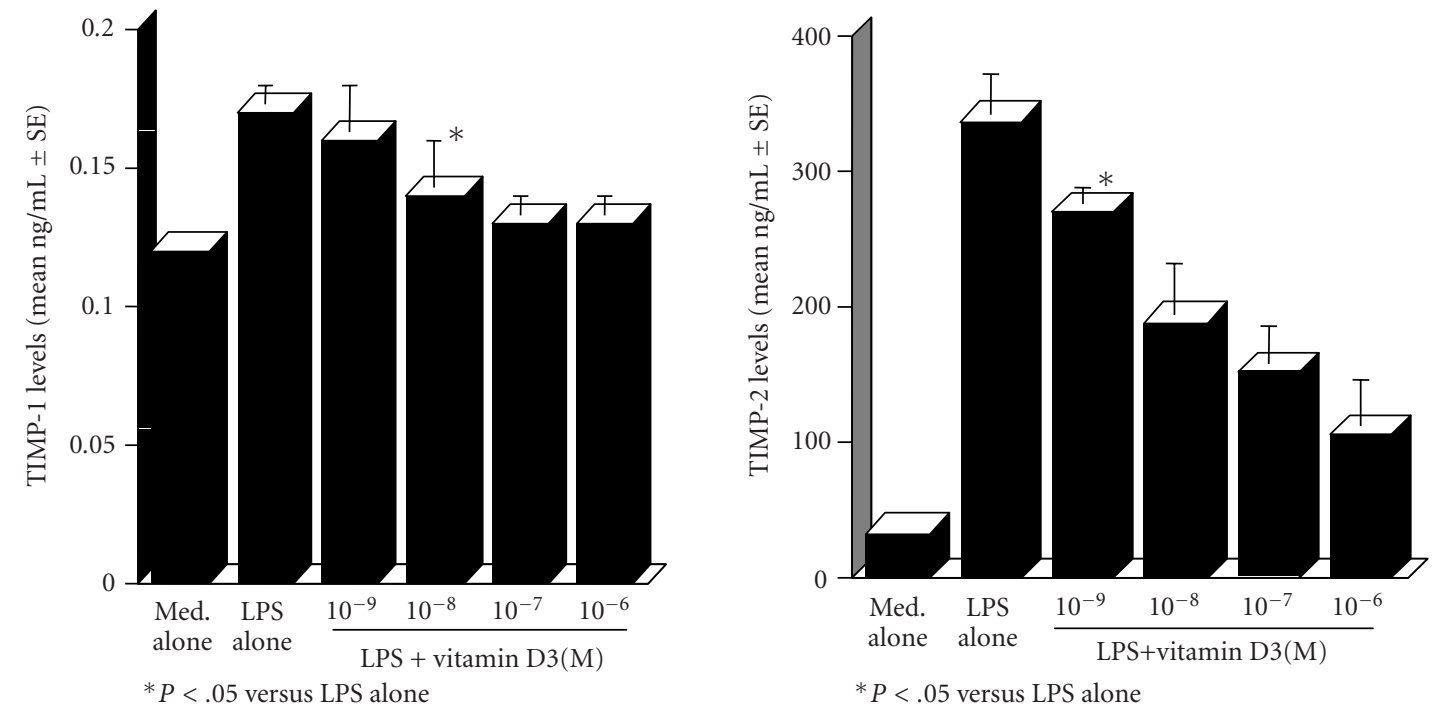

FIGURE 2. Suppressive activity of vitamin D3 on TIMP-1 and TIMP-2 production from keratinocytes in vitro. Details are shown in the legend of Figure 1.

examined the influence of VD3 on MMP-3 production from keratinocytes. VD3 exerted dose-dependent suppressive effects on MMP-3 production (Figure 1). The minimum concentration of VD3 which showed significant suppression was $10^{-8} \mathrm{M}$. The third set of experiments was performed to examine the influence of VD3 on TIMP-1 and TIMP-2 production from keratinocytes. The data in Figure 2 clearly showed the dose-dependent suppressive activity of VD3 on TIMP-1 and TIMP-2 production. The minimum concentrations of VD3 which showed significant suppression were $10^{-8} \mathrm{M}$ for TIMP-1 and $10^{-9} \mathrm{M}$ for TIMP-2.

\section{Influence of VD3 on mRNA expression}

The final set of experiments was carried out to examine the possible mechanisms by which VD3 could suppress the production of MMPs and TIMPs from keratinocytes in response to LPS stimulation. Cells were cultured with $100 \mu \mathrm{g} / \mathrm{mL}$ LPS in the presence of $0,10^{-9}, 10^{-8}$, 

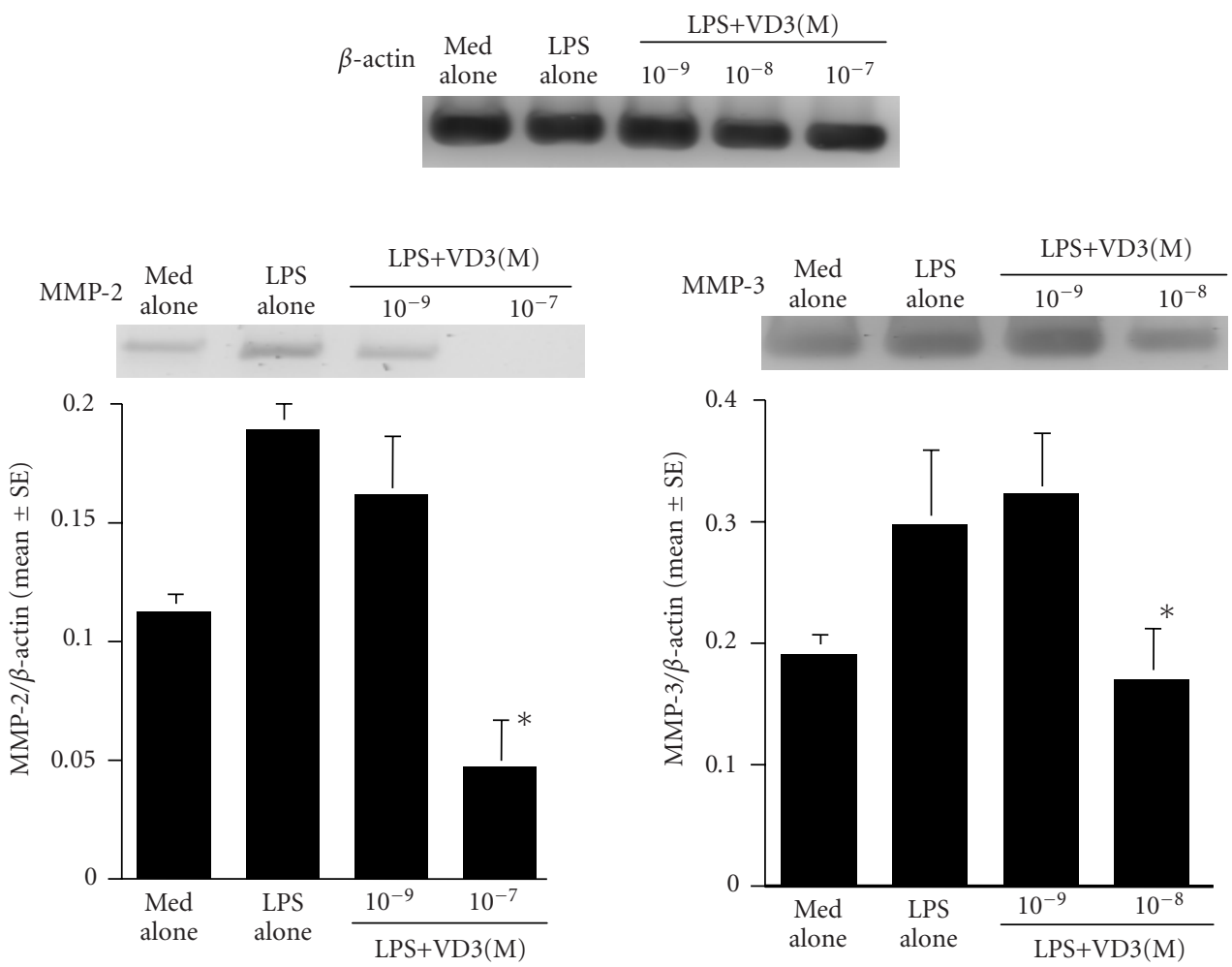

FIGURE 3. Influence of vitamin D3 on mRNA expression for MMP-2 and MMP-3 in keratinocytes after LPS stimulation. Keratinocytes $\left(2.5 \times 10^{5}\right.$ cells $\left./ \mathrm{mL}\right)$ derived from cholesteatoma tissues were stimulated with $100 \mu \mathrm{g} / \mathrm{mL}$ lipopolysaccharide (LPS) in the presence of various concentrations of vitamin D3 for 12 hours. mRNA expressions for MMP-2 and MMP-3 were examined by RT-PCR. Each set of data was expressed as the mean ratio (target/ $\beta$-actin) \pm SEM of five different subjects.

and $10^{-7} \mathrm{M}$ VD3 for 12 hours. Levels of mRNA expression were evaluated by RT-PCR. As shown in Figure 3, the addition of VD3 at $10^{-9} \mathrm{M}$ could not suppress the expression of mRNA for MMP-2 and MMP-3: these mRNA levels in cells treated with VD3 were nearly identical (not significant) to those observed in VD3-nontreated cells (LPS alone). However, MMP-2 mRNA expression was significantly suppressed by the addition of $10^{-7} \mathrm{M}$ VD3 (Figure 3). Similarly, MMP-3 mRNA expression was also suppressed by treatment of cell with $10^{-8} \mathrm{M}$ VD3 (Figure 3 ). We finally examined the influence of VD3 on TIMP mRNA expression. The data in Figure 4 clearly showed the suppressive activity of VD3 on TIMP mRNA expression in which the minimum concentrations of VD3 showing suppression of mRNA expression were $10^{-8} \mathrm{M}$ for TIMP1 and $10^{-9} \mathrm{M}$ for TIMP-2.

\section{DISCUSSION}

Cholesteatomas are characterised by abnormal cell proliferation resulting in the accumulation of keratin debris, destruction of the surrounding structures, and invasion of the inner ear or intracranial cavity. Although initial treatment of the cholesteatoma is accepted as consisting of careful cleaning of the ear and topical application of an- tibiotics or steroids, large or complicated cholesteatomas require surgical treatment to protect the patients from serious complications. In addition, cholesteatomas are well known to recur, even after surgical removal. Furthermore, a surgical procedure may not be possible in all cholesteatoma patients, such as elderly patients with a poor general medical condition. Therefore, the development of a minimally invasive agent or agents which could be used for the treatment of and prophylaxis against cholesteatomas has been strongly anticipated.

The present results clearly showed the suppressive effect of VD3 on the ability of keratinocytes to produce MMP-2 and MMP-3 in response to LPS stimulation. The study also demonstrated that VD3 exerted a suppressive effect on TIMP-1 and TIMP-2 production from keratinocytes induced by LPS stimulation. Moreover, these inhibitory actions of VD3 may be mediated, in part, by its suppressive effect on the expression of MMPs and TIMPs mRNA.

Histological observations of cholesteatoma tissues have revealed a benign keratinizing squamous cell cyst made up of three components, the cystic content, the matrix, and the perimatrix. The cystic content is composed of fully-differentiated nucleate keratine squames. The matrix contains the keratinizing squamous epithelium 

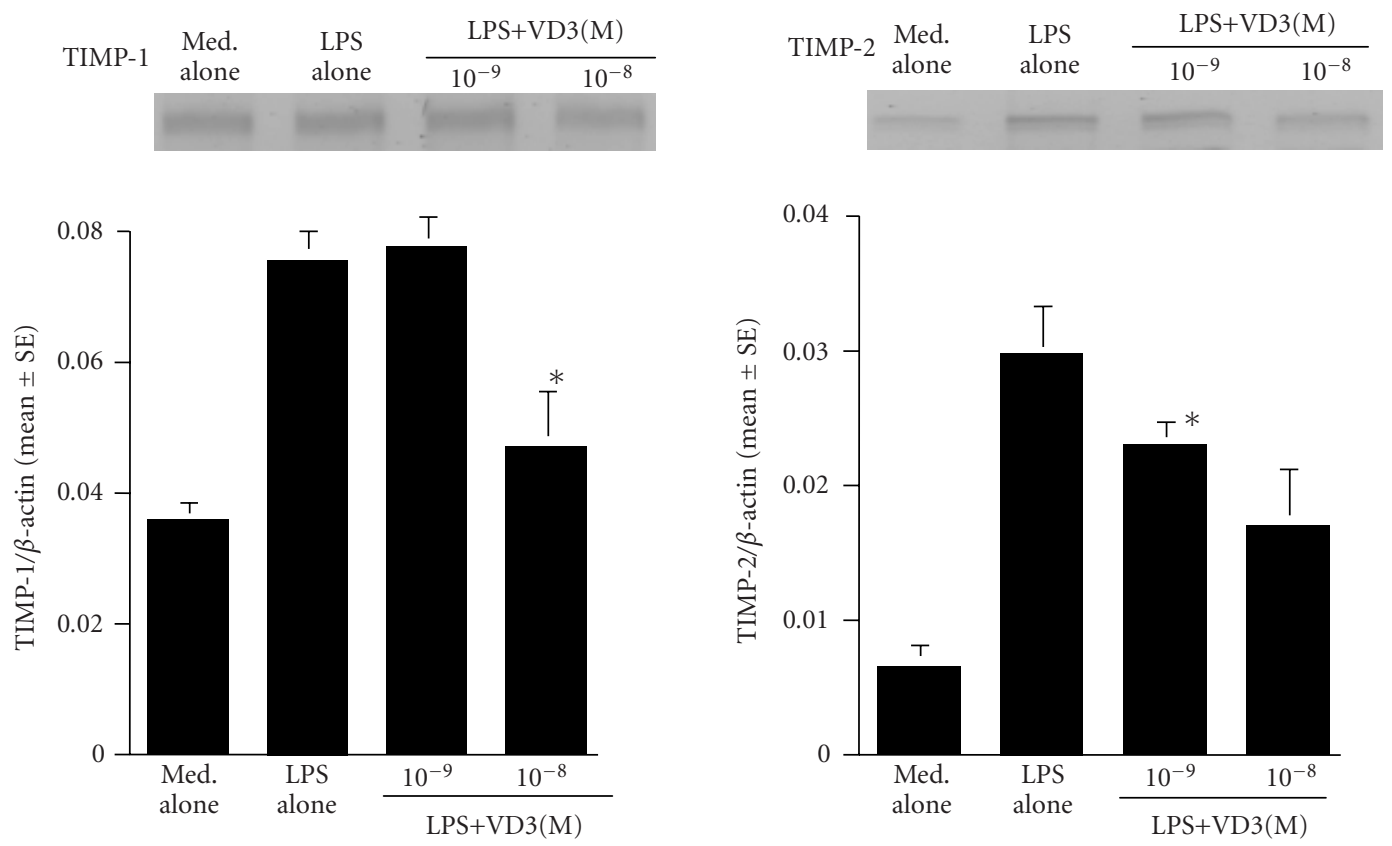

Figure 4. Influence of vitamin D3 on mRNA expression for TIMP-1 and TIMP-2 in keratinocytes after LPS stimulation. Details are shown in the legend of Figure 3.

lining a cyst-like structure. The perimatrix or lamina propria is the peripheral part of the cholesteatoma consisting of granulation tissue, which contains cholesterol crystals. The perimatrix layer is also in contact with bone and may result in bone destruction. These histological changes are now called tissue remodeling, and involve extensive alterations of the tissue ECM.

The ECM is involved in tissue homeostasis and in pathologic conditions such as tumour invasion and inflammation. Two groups of proteins, MMPs and their counter-regulatory inhibitors, TIMPs, are accepted to be the important factors for maintenance of ECM homoeostasis. The MMPs are a group of zinc-containing enzymes that are capable of digesting the ECM and basement membrane [13]. Among them, MMPs-2 and -3 degrade native type IV and VII collagen and denatured collagen, as well as laminin and proteoglycan, which are the most important components of ECM, basement membrane, and bone [14]. These MMPs are produced by numerous cell types, including keratinocytes and fibroblasts in response to inflammatory stimulation $[15,16]$. MMPs also appear to be responsible for microvascular permeability leading to oedema and enhancement of cell transmigration, especially in the case of osteoclasts $[15,16]$. From these reports, the present results showing the inhibitory action of VD3 on both MMP-2 and -3 production from keratinocytes may be interpreted to mean that topical application of VD3 to the external auditory canal and tympanic membrane could prevent the induction of cholesteatomas. This suggestion may be supported by the finding that topical application of VD3 can favourably modify psoriasis vulgaris skin lesions, which are characterised by the abnormal growth of keratinocytes with the intense infiltration of inflammatory cells $[17,18]$. Most MMPs are secreted from the cells as inactive proenzyme and cleaved extracellularly to produce the active forms [19]. The extracellular activity of MMPs is regulated by TIMPs, which are secreted by the same cell types that produce MMPs [19]. Besides MMP inhibitory activity, TIMPs have many biological functions associated with cell growth-stimulating activity [20]. The present results clearly showed that VD3 could suppress the ability of keratinocytes to produce TIMP-1 and TIMP-2, suggesting that VD3 could suppress abnormal cell growth in the surrounding tissues of cholesteatomas, and result in the inhibition of ECM remodeling and the development of cholesteatomas.

In conclusion, the present results might suggest that VD3 would be a good candidate for an agent in the medical treatment of or prophylaxis against cholesteatomas.

\section{REFERENCES}

[1] Shibosawa E, Tsutsumi K, Takakuwa T, Takahashi T. Stromal expression of matrix metalloprotease9 in middle ear cholesteatomas. Am J Otology. 2000;21(5):621-624.

[2] Madri JA, Basson MD. Extracellular matrix-cell interactions: dynamic modulators of cell, tissue and organism structure and function. Lab Invest. 1992;66(5):519-521. 
[3] Schmidt M, Grunsfelder P, Hoppe F. Up-regulation of matrix metalloprotease- 9 in middle ear cholesteatoma-correlations with growth factor expression in vivo? Eur Arch Otorhinolaryngol. 2001;258(9):472-476.

[4] Banerjee AR, James R, Narula AA, Lee RJ. Matrix metalloproteinase- 1 in cholesteatoma, middle ear granulations and deep meatal skin: a comparative analysis. Clin Otolaryngol. 1998;23(6):515-519.

[5] Schultz GS, Strelow S, Stern GA, et al. Treatment of alkali-injured rabbit corneas with a synthetic inhibitor of matrix metalloproteinases. Invest Ophthalmol Vis Sci. 1992;33(12):3325-3331.

[6] Cotter CS, Avidano MA, Stringer SP, Schultz GS. Inhibition of proteases in Pseudomonas otitis media in chinchillas. Otolaryngol Head Neck Surg. 1996;115(4):342-351.

[7] Lin R, Amizuka N, Sasaki T, et al. 1 Alpha, 25-dihydroxyvitamin D3 promotes vascularization of the chondro-osseous junction by stimulating expression of vascular endothelial growth factor and matrix metalloproteinase-9. J Bone Miner Res. 2002;17(9):1604-1612.

[8] Dean DD, Boyan BD, Schwart Z, et al. Effect of 1 alpha, 25-dihydroxyvitamin D3 on metalloproteinase activity and cell maturation in growth plate cartilage in vivo. Endocrine. 2001;14(3):311-323.

[9] Tetlow LC, Woolley DE. The effect of 1 alpha, 25dihydroxyvitamin D3 on matrix metalloproteinase and prostaglandin E2 production by cells of the rheumatoid lesion. Arthritis Res. 1999;1(1):63-70.

[10] O-Charoenrat P, Rhys-Evans P, Modjtahedi H, Court W, Box G, Eccles S. Overexpression of epidermal growth factor receptor in human head and neck squamous carcinoma cell lines correlates with matrix metalloproteinase- 9 expression and in vitro invasion. Int J Cancer. 2000;86(3):307-317.

[11] Yuan GH, Masuko-Hongo K, Sakata M, et al. The role of $\mathrm{C}-\mathrm{C}$ chemokines and their receptors in osteoarthritis. Arthritis Rheum. 2001;44(5):1056-1070.

[12] Moore BA, Aznavoorian S, Engler JA, Windsor LJ. Induction of collagenase-3 (MMP-13) in rheumatoid arthritis synovial fibroblasts. Biochim Biophys Acta. 2000;1502(2):307-318.

[13] Stetler-Stevenson WG. Dynamics of matrix turnover during pathologic remodeling of the extracellular matrix. Am J Pathol. 1996;148(5):1345-1350.

[14] Ishiguro $N$, Kojima $T$, Ito $T$, Iwata $H$. Matrix metalloproteinase-candidate for clinical joint destruction marker in arthropathy. Connective Tissue. 2001;33(1):43-49.

[15] Ohno I, Ohtani H, Nitta Y, et al. Eosinophils as a source of matrix metalloproteinase- 9 in asthmatic airway inflammation. Am J Respir Cell Mol Biol. 1997;16(3):212-219.

[16] Hoshino M, Nakamura Y, Sim J, Shimojo J, Isogai S. Bronchial subepithelial fibrosis and expression of matrix metalloproteinase- 9 in asthmatic airway inflammation. J Allergy Clin Immunol. 1998; 102(5):783-788.

[17] Kato K, Rokugo M, Terui T, Tagami H. Successful treatment of psoriasis with topical application of active vitamin D3 analogue, $1 \alpha$, 24-dihydroxycholecalciferol. British J Dermatol. 1986;115:431-433.

[18] Ueda K, Suzuki H, Nakagawa S, Kawahara K. Light microscopic and electron microscopic studies on the guinea pig skin and the lesions of psoriasis vulgaris after topical application of $1 \alpha$, 24-dihydroxycholecalciferol. Acta Dermatol (Kyoto). 1989;84:341-358.

[19] Birkedal-Hansen H, Moore WG, Bodden MK, et al. Matrix metalloproteinases: a review. Crit Rev Oral Biol Med. 1993;4(2):197-250.

[20] Hayakawa T. Structures and functions of TIMPs. Connective Tissue. 2001;33(1):33-42. 


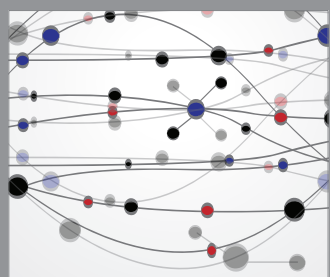

The Scientific World Journal
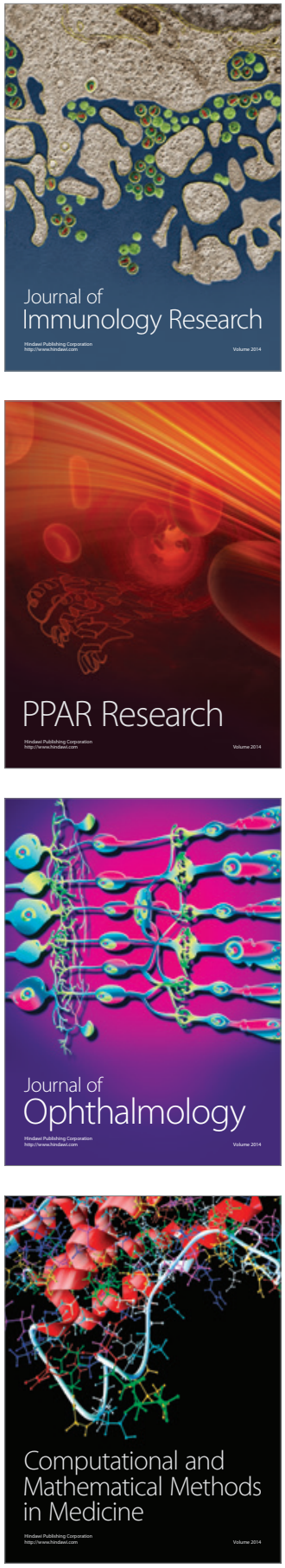

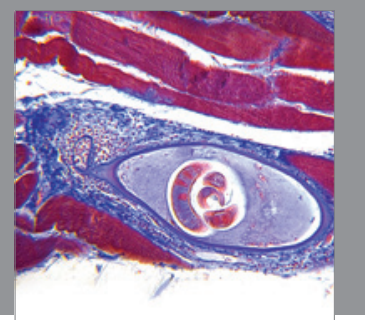

Gastroenterology

Research and Practice
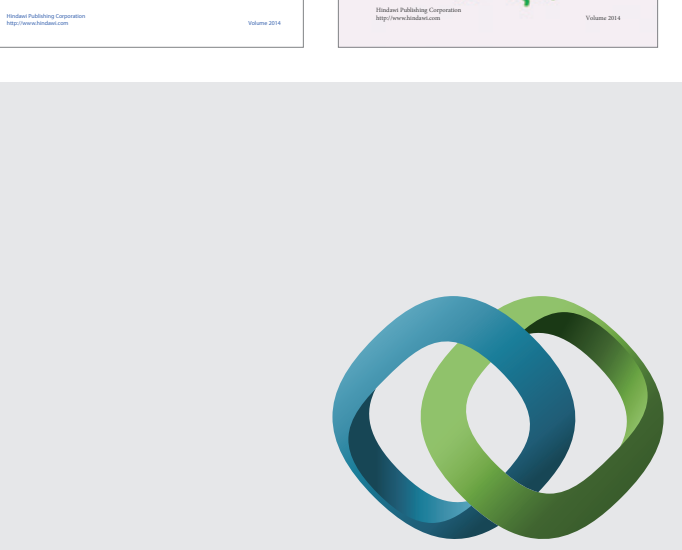

\section{Hindawi}

Submit your manuscripts at

http://www.hindawi.com
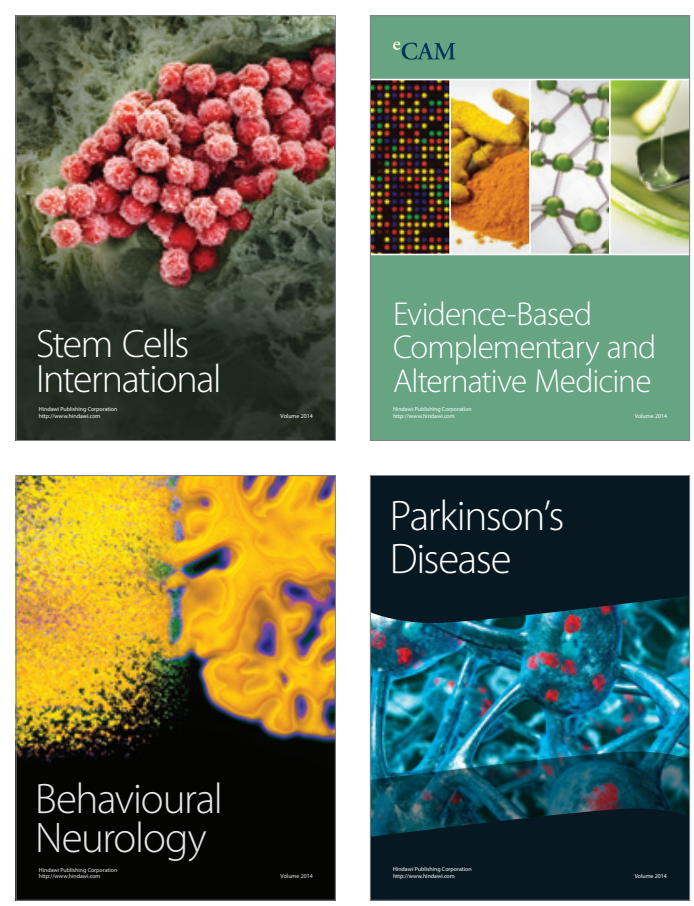

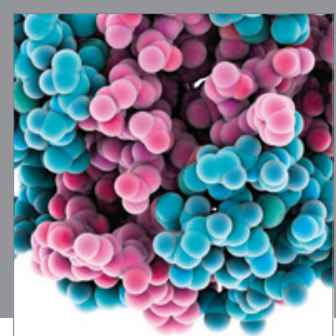

Journal of
Diabetes Research

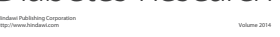

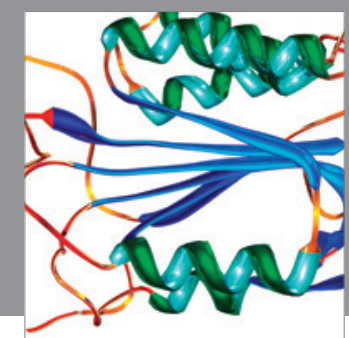

Disease Markers
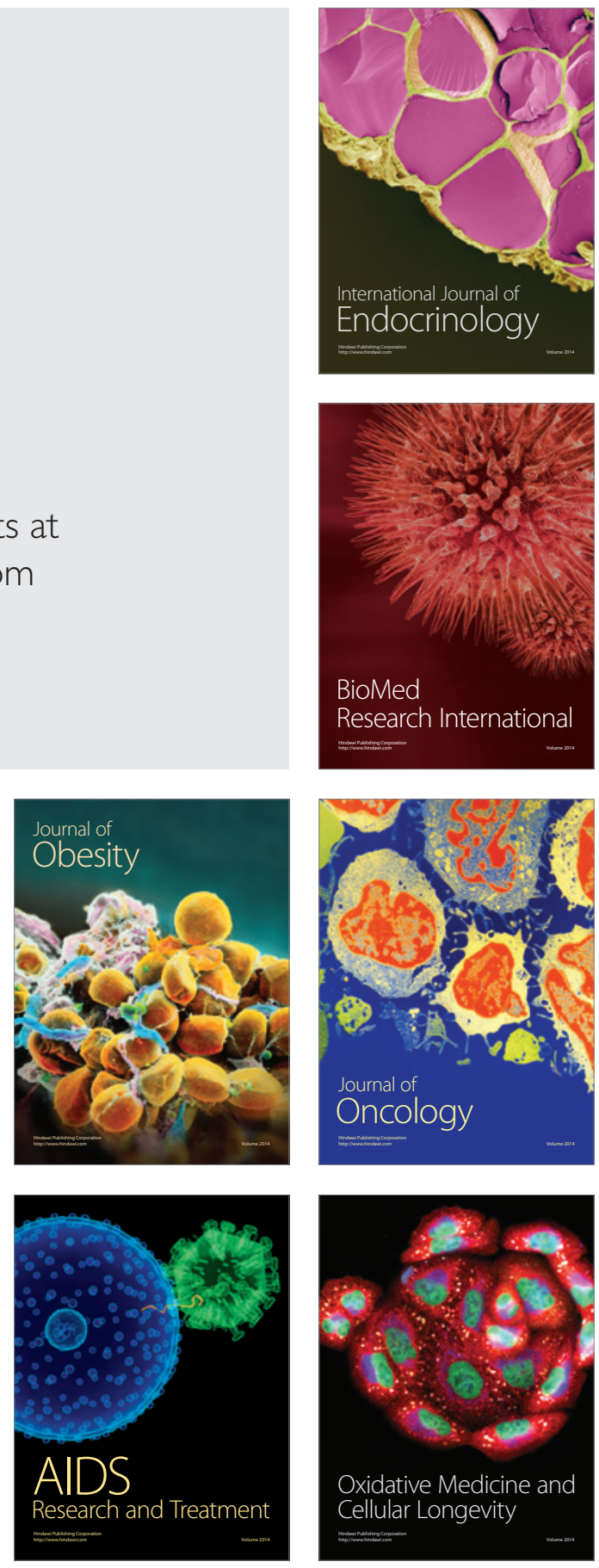